\title{
Glass formation range of Mg-based bulk metallic alloys
}

\author{
J.L. Soubeyroux ${ }^{1, a}$, S. Gorsse ${ }^{2, b}$ and G. Orveillon ${ }^{2, c}$ \\ ${ }^{1}$ Laboratoire de Crystallographie / CRETA / CNRS, 25 avenue des Martyrs, 38042 \\ Grenoble, France \\ ${ }^{2}$ Institut de Chimie de la Matière Condensée de Bordeaux / CNRS, 87 Avenue du Dr. \\ Albert Schweitzer , 33608 Pessac France \\ asoubeyroux@grenoble.cnrs.fr, ${ }^{b}$ gorsse@icmcb-bordeaux.cnrs.fr, ${ }^{\text {a }}$ orveillo@icmcb- \\ bordeaux.cnrs.fr
}

Keywords: Magnesium alloys, Bulk metallic glass, Glass forming ability

\begin{abstract}
New bulk metallic glasses (BMG) have been synthesized in the Mg-Cu-RE systems $(\mathrm{RE}=\mathrm{Y}, \mathrm{Gd})$ with high critical diameter. In order to determine the glass forming range of these ternary systems, the calculation of the onset of driving forces (ODF) has been performed and has shown a large composition range for BMG formation. The synthesis of particular compositions in this domain has shown that all the produced alloys present a high glass forming ability (GFA) measured by DSC experiments. The ODF model, synthesized alloys by mould casting, characterization by X-ray diffraction and DSC techniques are presented.
\end{abstract}

\section{Introduction}

Bulk metallic glasses (BMG) exhibit particularly attractive mechanical properties like high stresses to fracture and large elastic strains. Mg-based BMG are of special interest since they can provide the possibility to obtain new light alloys for structural applications. For shaping by hot deformation, it is important to produce alloys with a large temperature range between the vitrous temperature transition and the crystallization temperature. It is also important to produce alloys with a high critical diameter (or thickness) in order to produce thick pieces with the vitrous characteristics responsible of the good mechanical properties. For industrial development, the amount of the rareearth metal must be as low as possible and the use of expensive additives, such as silver for example, must be avoided. The nature of the rare earth through its weight, price and handling conditions are also important. Yttrium and gadolinium have been chosen as yttrium is light but the alloy formed must be casted under argon, on the other hand gadolinium is heavier but the alloy can be casted under air. Most of previous studies were focused on $\mathrm{Mg}_{65} \mathrm{Cu}_{25} \mathrm{Y}_{10}$ [1] or $\mathrm{Mg}_{60} \mathrm{Cu}_{30} \mathrm{Y}_{10}$ 
[2,3] compositions and more recently $\mathrm{Mg}_{65} \mathrm{Cu}_{25} \mathrm{Gd}_{10}$ composition was introduced by $\mathrm{Ma}$ [4]. The effects of mixed Y-Gd compounds have been studied in $[5,6]$. The search for new alloys in a ternary or quaternary system can be simplified by the use of empirical laws as developed by Inoue [7], by a structural approach [8], or by thermodynamic approaches to predict the best glass forming ranges for the quenched alloys [9].

In the present work, driving forces for primary crystal nucleation from undercooled liquid were calculated over the whole composition space in the $\mathrm{Mg}-\mathrm{Cu}-\mathrm{Y}$ system. New alloys with good glass forming abilities (GFA) were synthesized in the predicted glass forming composition range. We have also extended the synthesis to the $\mathrm{Mg}-\mathrm{Cu}-\mathrm{Gd}$ system with success. Several new compositions have been prepared in a cone-shaped copper mould in order to determine the upper diameter critical limit by X-ray diffraction. Differential scanning calorimetry (DSC) analysis were carried out to determine glass transition $\left(\mathrm{T}_{\mathrm{g}}\right)$, crystallization $\left(\mathrm{T}_{\mathrm{x}}\right)$, liquidus $\left(\mathrm{T}_{1}\right)$ and melting $\left(\mathrm{T}_{\mathrm{m}}\right)$ temperatures with the aim to calculate usual GFA indicators: $\gamma=\mathrm{T}_{\mathrm{x}} /\left(\mathrm{T}_{\mathrm{g}}+\mathrm{T}_{1}\right), \mathrm{T}_{\mathrm{rg}}=\mathrm{T}_{\mathrm{g}} / \mathrm{T}_{\mathrm{r}}$ and $\Delta \mathrm{T}=\mathrm{T}_{\mathrm{x}}-\mathrm{T}_{\mathrm{g}}$.

\section{Modeling}

According to the classical theory of nucleation, the rate of the steady-state nucleation of a new phase is exponentially proportional to the height of the nucleation energy barrier. This quantity, which represents the work required to form one critical nucleus, depends on the solid/liquid interfacial energy and the chemical driving force for nucleation. There is a lack of data on the surface energies; however, the driving forces are the main factor that affects nucleation kinetics $[10,11]$ and can be calculated if the Gibbs free energies of the crystalline phases are known.

The thermodynamic calculations were performed using a critically assessed thermodynamic database [12]. In this study the $\mathrm{Mg}-\mathrm{Cu}-\mathrm{Y}$ system consists of four solution phases (bcc, fcc and hcp terminal solid solutions, and liquid) described by a regular solution model, and eleven binary compounds $\left(\mathrm{Cu}_{2} \mathrm{Y}\right.$ hexagonal and rhombohedral, $\mathrm{CuY}, \mathrm{Cu}_{7} \mathrm{Y}_{2}, \mathrm{Cu}_{4} \mathrm{Y}, \mathrm{Cu}_{6} \mathrm{Y}, \mathrm{Cu}_{2} \mathrm{Mg}, \mathrm{CuMg}_{2}, \mathrm{MgY}$, $\mathrm{Mg}_{2} \mathrm{Y}$ and $\mathrm{Mg}_{24} \mathrm{Y}_{5}$ ).

The onset driving forces $\left(\mathrm{ODF}^{\varepsilon}\right)$ associated with the beginning of the precipitation of a given crystalline phase, $\varepsilon$, from undercooled liquid can be expressed as:

$O D F^{\varepsilon}=x_{A}^{\varepsilon} \cdot G_{A}^{L}\left(x_{B}^{L}\right)+x_{B}^{\varepsilon} \cdot G_{B}^{L}\left(x_{B}^{L}\right)-G_{m}^{\varepsilon}\left(x_{B}^{\varepsilon}\right)$

where $G_{A}^{L}\left(x_{B}^{L}\right)$ and $G_{B}^{L}\left(x_{B}^{L}\right)$ are the chemical potentials of $\mathrm{A}$ and $\mathrm{B}$ in the liquid phase for a given composition $x_{B}^{L}$, and $G_{m}^{\varepsilon}\left(x_{B}^{\varepsilon}\right)$ is the Gibbs free energy of the new phase $\varepsilon$.

\section{Experimental procedure}


Elements with purity better than $99.9 \%$ were used as starting materials. $\mathrm{Cu}-\mathrm{Y}$ or $\mathrm{Cu}-\mathrm{Gd}$ as intermediate alloys were melted prior to be re-melted with $\mathrm{Mg}$ to obtain the master alloy. The glasses were prepared by copper mould casting in a cone-shaped mould that diameter was varying from 4 to $12 \mathrm{~mm}$.

The degree of amorphicity was characterized by X-ray diffraction (XRD) analyses using $\mathrm{Cu}$ radiation for a $2 \Theta$ range $20-80^{\circ}$. The thermal glass stability was determined by differential scanning calorimetry (Netzsch DSC 404S). The analyses were carried out with a heating rate of $10 \mathrm{~K} / \mathrm{min}$ under flowing argon gas. After each run, a second run was performed in order to estimate the baseline. From DSC analyses, the characteristic temperatures $T_{g}$ (glass transition temperature), $T_{x}$ (onset of crystallization), $\mathrm{T}_{\mathrm{m}}$ (onset of melting), and $\mathrm{T}_{1}$ (end of melting) were measured. The thermal parameters: and $\Delta \mathrm{T}=\mathrm{T}_{\mathrm{x}}-\mathrm{T}_{\mathrm{g}}, \mathrm{T}_{\mathrm{rg}}=\mathrm{T}_{\mathrm{g}} / \mathrm{T}_{\mathrm{m}}$ [13] and $\gamma=\mathrm{T}_{\mathrm{x}} /\left(\mathrm{T}_{\mathrm{g}}+\mathrm{T}_{1}\right)$ [14] were calculated from these data.

\section{Results and discussion}

Figure 1 shows the calculated two-dimensional section onset driving forces (ODF's) for the primary crystal formation from the undercooled liquid in $\mathrm{Mg}_{\mathrm{x}} \mathrm{Cu}$ 90-x $\mathrm{Y}_{10}$ alloys, where $\mathrm{x}=0$ to 90 at.\%. The ODF's were calculated at $\mathrm{T}=600 \mathrm{~K}$ as a function of the $\mathrm{Mg}$ content. These calculations show that, in the given composition range, $\mathrm{Cu}_{6} \mathrm{Y}, \mathrm{Cu}_{4} \mathrm{Y}, \mathrm{MgCu}_{2}, \mathrm{Mg}_{2} \mathrm{Cu}$ and $\mathrm{Mg}_{24} \mathrm{Y}_{5}$ phases exhibit the highest driving force for crystallization. For $\mathrm{Mg}$ contents ranging from 48 to 70 at.\%, the $\mathrm{Mg}_{2} \mathrm{Cu}$ phase has the highest tendency to nucleate. This result is in agreement with the devitrification sequence of the $\mathrm{Mg}_{65} \mathrm{Cu}_{25} \mathrm{Y}_{10}$ glassy alloy observed by Men et al. [15]. One can also see in Figure 1, that $\mathrm{Mg}_{60} \mathrm{Cu}_{30} \mathrm{Y}_{10}$ and $\mathrm{Mg}_{65} \mathrm{Cu}_{25} \mathrm{Y}_{10}$ alloys, which are known to have good glass forming abilities (GFA), are located in a local minimum of the ODFs. A smaller ODF value generally indicates a higher crystallization resistance or a better ability for glass formation [10,11]. The best glass forming range for producing alloys with good GFA may therefore reasonably be predicted analytically from a complete three-dimensional plot of the ODF for the full composition space. In Figure 2, the projection of the ODF calculated in the $\mathrm{Mg}-\mathrm{Cu}-\mathrm{Y}$ system at $600 \mathrm{~K}$ is reported. Figure 2 indicates the presence of ODF minima along a composition line that contains previously determined alloys $\mathrm{Mg}_{65} \mathrm{Cu}_{25} \mathrm{Y}_{10}$ and $\mathrm{Mg}_{58.5} \mathrm{Cu}_{30.5} \mathrm{Y}_{11}$ with high GFA [16, 19]. In this study several alloys with compositions ranging along this line of ODF minima, from $\mathrm{Mg}_{72} \mathrm{Cu}_{20} \mathrm{Y}_{8}$ to $\mathrm{Mg}_{45} \mathrm{Cu}_{37} \mathrm{Y}_{18}$, were produced. The same compositions were synthesized in the $\mathrm{Mg}-\mathrm{Cu}-\mathrm{Gd}$ system. Table I shows the alloys studied and the results of the DSC measurements compared with same previous data of literature.

Fig. 3 displays XRD patterns taken from the cross-section of the cone at different diameters for some compositions, confirming the amorphous structure of the as-cast alloy up to at least 5 
millimetres in diameter for all compositions. For the higher diameters, one small peak appears at $2 \Theta=41^{\circ}$, originating from $\mathrm{Cu}_{2} \mathrm{Gd}$.

Fig. 4a and Fig. 4b show the corresponding DSC traces for the yttrium and gadolinium systems respectively. All the compositions show a marked glass transition, with a main crystallization event around $500 \mathrm{~K}$ and a main melting event around $700 \mathrm{~K}$. For some compositions there is a small second crystallization event and a second melting component (for the alloys with the higher rare earth content).

The $\gamma$ parameter and the critical diameter have been reported in Fig. 5 as a function of the gadolinium content, both present a maximum around 14\% and 12\% respectively, but indicating very high GFA for compositions between 10 and 15\%. The $\gamma$ parameter is in good agreement with the higher critical diameters measured for these alloys and reflects a posteriori the possibility to obtain very thick glasses.

The search for BMGs along the line calculated by the ODF method shows that all the reported compositions are BMGs with critical diameter above 5 millimeters. Even for a magnesium composition of $72 \mathrm{at} \%$, it exists a BMG with good GFA what is promising for applications of magnesium alloys at low cost. The minimum in the ternary eutectic does not correspond to the best composition, for example the synthesis of the $\mathrm{Mg}_{50} \mathrm{Cu}_{35} \mathrm{Y}_{15}$ alloy, a minimum in liquidus, has not lead to any BMG formation for diameter down to $4 \mathrm{~mm}$. This observation was already made for other liquidus minimum compositions where the best glass forming compounds were found at different compositions [18]. The data calculated for the yttrium alloys have been extended to the gadolinium alloys with success, however a best knowledge of the $\mathrm{Mg}$-Cu-Gd ternary phase diagram should propose a slightly different calculation for the ODF map and consequently slightly different better compositions. We are also working to extend the model to quaternary systems with low additions.

DSC traces show high $T_{g}$ and $T_{x}$ and large $\Delta T$ enabling these alloys to be deformed with a low strength and at a moderate temperature. However, these alloys are still brittle and improvements have to be done before applications.

\section{Conclusion}

The thermodynamic approach based on the evaluation of the onset driving forces for nucleation seems to be a very promising method to determine the compositions to synthesize in order to obtain thick bulk metallic glasses. Concerning the particular alloys obtained in this study, the best compositions studied are for a rare earth content of 11 or $12 \%$, they present a high crystallization temperature $(\approx 396 \mathrm{~K}$ for $\mathrm{Y}, \approx 385 \mathrm{~K}$ for $\mathrm{Gd})$, a high melting temperature $(\approx 730 \mathrm{~K}$ for $\mathrm{Y}, \approx 708 \mathrm{~K}$ for $\mathrm{Gd})$, a large $\Delta \mathrm{T}(75-70 \mathrm{~K})$ and a high $\gamma$ value $(>0.41)$, samples with 10 millimeter diameter are 
almost fully amorphous with the presence of a minor crystallized fraction that could have a good influence on mechanical properties. Mechanical properties under compression at room temperature and in the $\Delta \mathrm{T}$ range are under investigations.

\section{References}

[1] W. Liu, W.L. Johnson, J. Mater. Res., 11 (1996) 2388.

[2] K. Amiya, A. Inoue, Mater. Trans. JIM, 41 (2000) 1460.

[3] S. Linderoth, N.H. Pryds, M. Ohnuma, A.S. Pedersen, M. Eldrup, N. Nishiyama, A. Inoue, Mat. Sci. Eng., A304-306 (2001) 656

[4] H. Ma, E. Ma, J. Xu, J. Mater. Res., 18 (2003) 2288.

[5] Z. Kovacs, A. Castellero, A.L. Greer, J. Lendvai, M. Baricco, Mater. Sci. Eng., A387-389 (2004) 1012.

[6] J.L. Soubeyroux, S. Puech, J.J. Blandin, Mat. Sci. Eng. A, RQ12 proceedings (2005)

[7] A. Inoue, Acta Mater. 48 (2000) 279.

[8] D.B. Miracle, Nat. Mater., 3 (2004) 697.

[9] A. Zhu, G.J. Shiflet, D.B. Miracle, Scripta Materialia, 50 (2004) 987-991.

[10] D. Kim, B.J. Lee, N.J. Kim, Intermetallics, 12 (2004) 1103-1107.

[11] D. Kim, B.-J. Lee, N.J. Kim, Scripta Materialia, 52 (2005) 969-972.

[12] COST2 - TCOST507 Light Alloys Database (Version 2.1), provided by TCSAB, 1999/2003.

[13] E.S. Park, D.H. Kim, W.T. Kim, Appl. Phys. Lett., 86 (2005) 61907.

[14] X.K. Xi, D.Q. Zhao, M.X. Pan, W.H. Wang, Intermetallics, 13 (2005) 638.

[15] H. Men, W.T; Kim, D.H. Kim, J. Of Non-Cryst. Solids, 337 (2004) 29-35.

[16] A. Inoue, T. Masumoto, Mat. Sci. And Eng., A173 (1993) 1

[17] N.H. Pryds, M. Eldrup, M. Ohnuma, A.S. Pedersen, J. Hattel, S. Linderoth, Mat. Trans., JIM, $41(2000) 1435$.

[18] Z.P. Lu, C.T. Liu, Phys. Rev. Lett., 91 (2003) 115505.

[19] H. Ma, Q. Zheng, J. Xu, Y. Li, E. Ma, J. Mater. Res., 20 (2005) 2252.

[20] E.S. Park, D.H. Kim, J. Mater. Res., 20 (2005) 1465. 
Table I: Measured thermal parameters $\left(\mathrm{T}_{\mathrm{g}}, \mathrm{T}_{\mathrm{x}}, \mathrm{T}_{\mathrm{m}}\right.$ and $\left.\mathrm{T}_{1}\right)$ with the calculated parameters $\mathrm{T}_{\mathrm{rg}}=\mathrm{T}_{\mathrm{g}} / \mathrm{T}_{\mathrm{m}}$ and $\gamma=\mathrm{T}_{\mathrm{x}} /\left(\mathrm{T}_{\mathrm{g}}+\mathrm{T}_{1}\right)$ and the measured critical diameters (Dc) for the $\mathrm{Mg}_{\mathrm{x}} \mathrm{Cu}_{\mathrm{y}} \mathrm{Y}_{\mathrm{z}}$ and $\mathrm{Mg}_{\mathrm{x}} \mathrm{Cu}_{\mathrm{y}} \mathrm{Gd}_{\mathrm{z}}$ systems. (DSC traces measured at

$10 \mathrm{~K} / \mathrm{min})$.

\begin{tabular}{|c|c|c|c|c|c|c|c|c|c|c|c|c|}
\hline At.\% Mg & At.\% Cu & At.\% Y & $\operatorname{Tg}(\mathrm{K})$ & $\operatorname{Tx}(\mathrm{K})$ & $\Delta \mathrm{T}(\mathrm{K})$ & $\mathrm{Tm}_{\mathrm{i}}(\mathrm{K})$ & $\mathrm{Tm}_{\mathrm{f}}(\mathrm{K})$ & $\Delta \mathrm{Tm}(\mathrm{K})$ & $\operatorname{Trg}$ & $\gamma$ & Dc $(\mathrm{mm})$ & Reference \\
\hline 72 & 20 & 8 & 411 & 456 & 45 & 693 & 756 & 63 & $\mathbf{0 , 5 9 3 1}$ & $\mathbf{0 , 3 9 0 7}$ & 5 & \\
\hline 65 & 25 & 10 & 427 & 485 & 58 & 740 & 768 & 28 & $\mathbf{0 , 5 7 7 0}$ & $\mathbf{0 , 4 0 5 9}$ & 5 & \\
\hline 65 & 25 & 10 & 417 & 480 & 63 & 726 & 737 & 11 & $\mathbf{0 , 5 7 4 4}$ & $\mathbf{0 , 4 1 5 9}$ & 4 & {$[19]$} \\
\hline 58,5 & 30,5 & 11 & 429 & 498 & 69 & 735 & 782 & 47 & $\mathbf{0 , 5 8 3 7}$ & $\mathbf{0 , 4 1 1 2}$ & 9 & {$[6]$} \\
\hline 58,5 & 30,5 & 11 & 422 & 496 & 74 & 729 & 762 & 33 & $\mathbf{0 , 5 7 8 9}$ & $\mathbf{0 , 4 1 8 9}$ & 9 & {$[19]$} \\
\hline 58 & 30 & 12 & 426 & 494 & 68 & 730 & 771 & 41 & $\mathbf{0 , 5 8 3 6}$ & $\mathbf{0 , 4 1 2 7}$ & 9 & \\
\hline 51 & 34 & 15 & 439 & 497 & 58 & 732 & 781 & 49 & $\mathbf{0 , 5 9 9 7}$ & $\mathbf{0 , 4 0 7 4}$ & 5 & \\
\hline 45 & 37 & 18 & 444 & 499 & 55 & 732 & 829 & 97 & $\mathbf{0 , 6 0 6 6}$ & $\mathbf{0 , 3 9 2 0}$ & 5 & \\
\hline
\end{tabular}

\begin{tabular}{|c|c|c|c|c|c|c|c|c|c|c|c|c|}
\hline At.\% Mg & At.\% Cu & At.\% Gd & $\operatorname{Tg}(\mathrm{K})$ & $\operatorname{Tx}(\mathrm{K})$ & $\Delta \mathrm{T}(\mathrm{K})$ & $\operatorname{Tm}_{\mathrm{i}}(\mathrm{K})$ & $\operatorname{Tm}_{\mathrm{f}}(\mathrm{K})$ & $\Delta \mathrm{Tm}(\mathrm{K})$ & $\operatorname{Trg}$ & $\gamma$ & Dc $(\mathrm{mm})$ & Reference \\
\hline 72 & 20 & 8 & 411 & 454 & 43 & 673 & 745 & 72 & $\mathbf{0 , 6 1 0 7}$ & $\mathbf{0 , 3 9 2 7}$ & 6 & \\
\hline 65 & 25 & 10 & 413 & 473 & 60 & 695 & 739 & 44 & $\mathbf{0 , 5 9 4 2}$ & $\mathbf{0 , 4 1 0 6}$ & 7 & \\
\hline 65 & 25 & 10 & 423 & 484 & 61 & 679 & 740 & 61 & $\mathbf{0 , 6 2 3 0}$ & $\mathbf{0 , 4 1 6 2}$ & 8 & {$[20]$} \\
\hline 58,5 & 30,5 & 11 & 426 & 490 & 64 & 709 & 753 & 44 & $\mathbf{0 , 6 0 0 8}$ & $\mathbf{0 , 4 1 5 6}$ & 9 & {$[6]$} \\
\hline 58 & 30 & 12 & 424 & 485 & 61 & 705 & 755 & 50 & $\mathbf{0 , 6 0 1 4}$ & $\mathbf{0 , 4 1 1 4}$ & 9 & \\
\hline 51 & 34 & 15 & 432 & 494 & 62 & 711 & 747 & 36 & $\mathbf{0 , 6 0 7 6}$ & $\mathbf{0 , 4 1 9 0}$ & 6 & \\
\hline 45 & 37 & 18 & 441 & 495 & 54 & 705 & 785 & 80 & $\mathbf{0 , 6 2 5 5}$ & $\mathbf{0 , 4 0 3 8}$ & 5 & \\
\hline
\end{tabular}

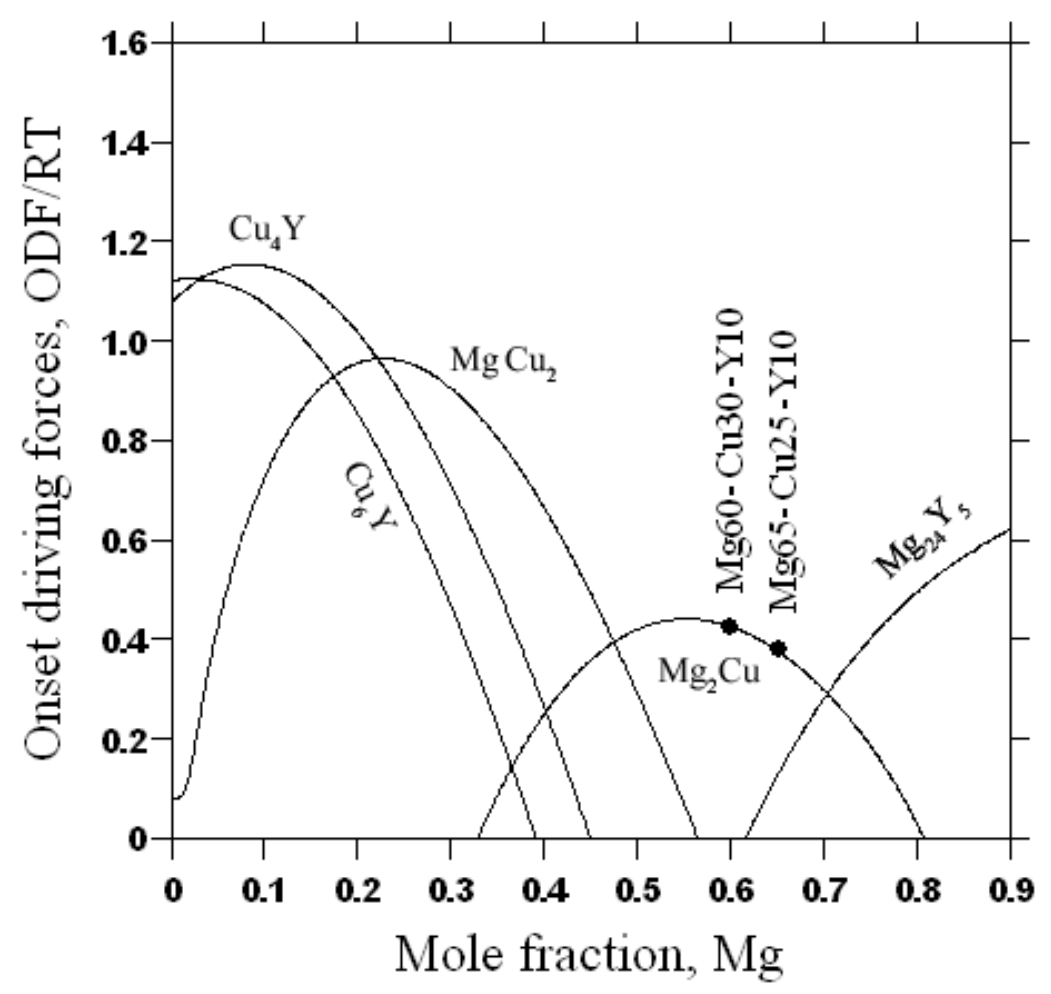

Figure 1: Calculated onset driving forces of various crystalline phases for $\mathrm{Mg}_{\mathrm{x}} \mathrm{Cu}_{90-\mathrm{x}} \mathrm{Y}_{10}$ alloys versus $\mathrm{Mg}$ content at 600 $\mathrm{K}$. The circles represent the alloy compositions usually reported in the bibliography and known as good glass formers with critical diameters up to $7 \mathrm{~mm}$. 


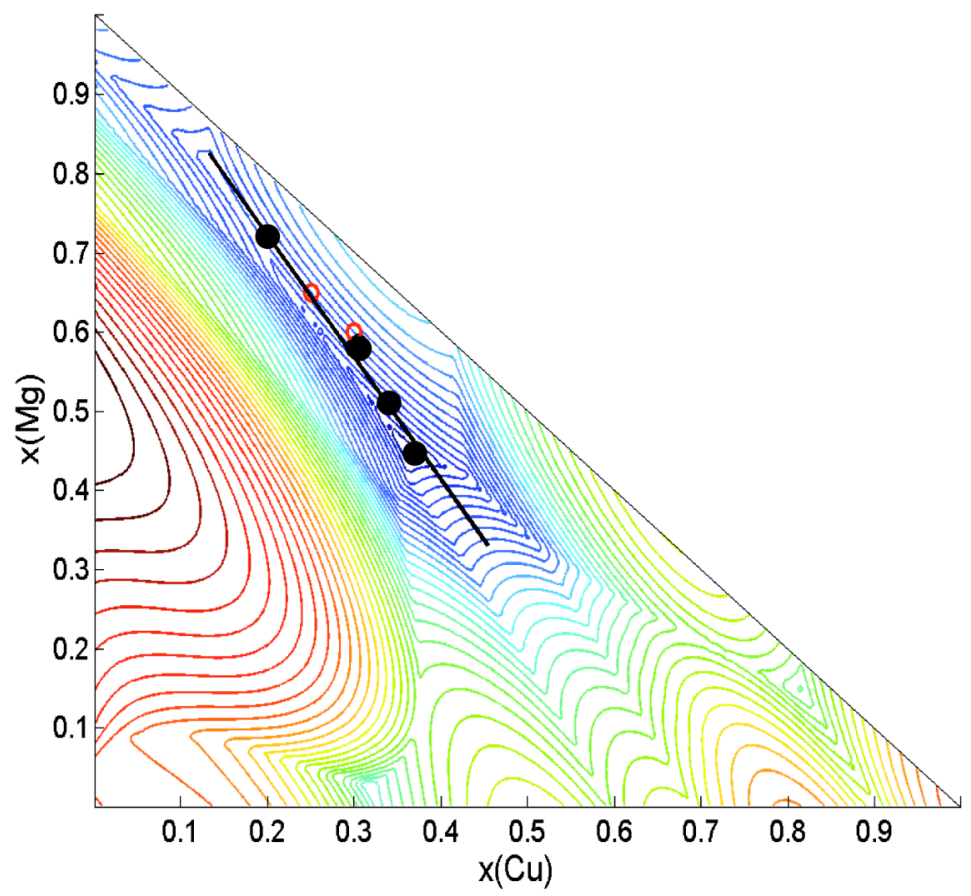

Figure 2: Projected onset driving forces for the $\mathrm{Mg}-\mathrm{Cu}-\mathrm{Y}$ ternary system. $\mathrm{x}_{\mathrm{Cu}}$ and $\mathrm{x}_{\mathrm{Mg}}$ are respectively the mole fraction of copper and magnesium. "Iso-ODF" lines are displayed gradually from high values (red) to low values (dark blue). The line is a guide for the eye for the region of ODF's minima. Black dots are the experimental points of this study. Red dots (empty circles) are the points for $\mathrm{Mg}_{65} \mathrm{Cu}_{25} \mathrm{Y}_{10}$ and $\mathrm{Mg}_{60} \mathrm{Cu}_{30} \mathrm{Y}_{10}$, compounds known as good glass formers.

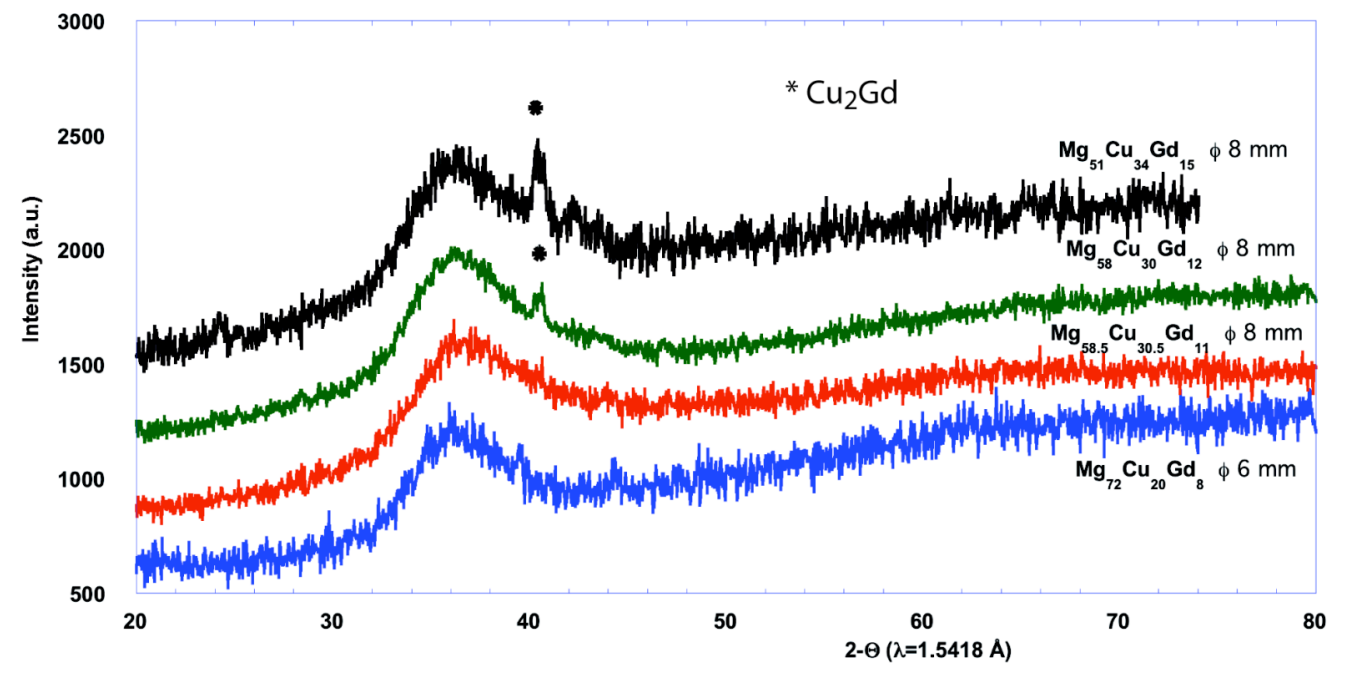

Figure 3: X-ray diffraction patterns of the $\mathrm{Mg}_{x} \mathrm{Cu}_{x} \mathrm{Gd}_{z} \mathrm{BMG}$ alloys obtained at different sections of the conical samples. 


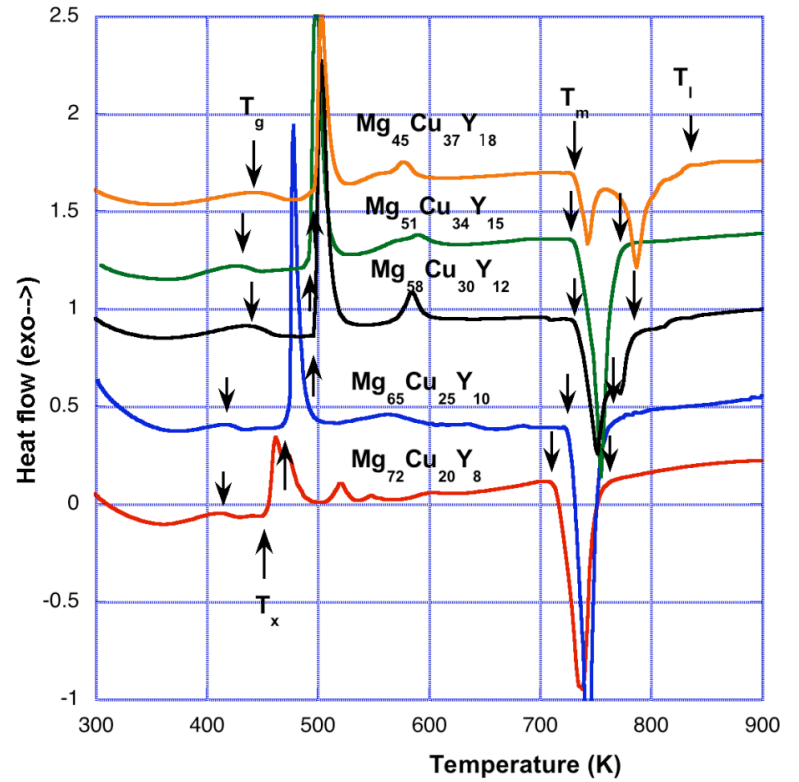

Fig. 4a: DSC traces of the $\mathrm{Mg}_{\mathrm{x}} \mathrm{Cu}_{\mathrm{y}} \mathrm{Y}_{\mathrm{z}}$ BMG alloys obtained at $10 \mathrm{~K} / \mathrm{min}$.

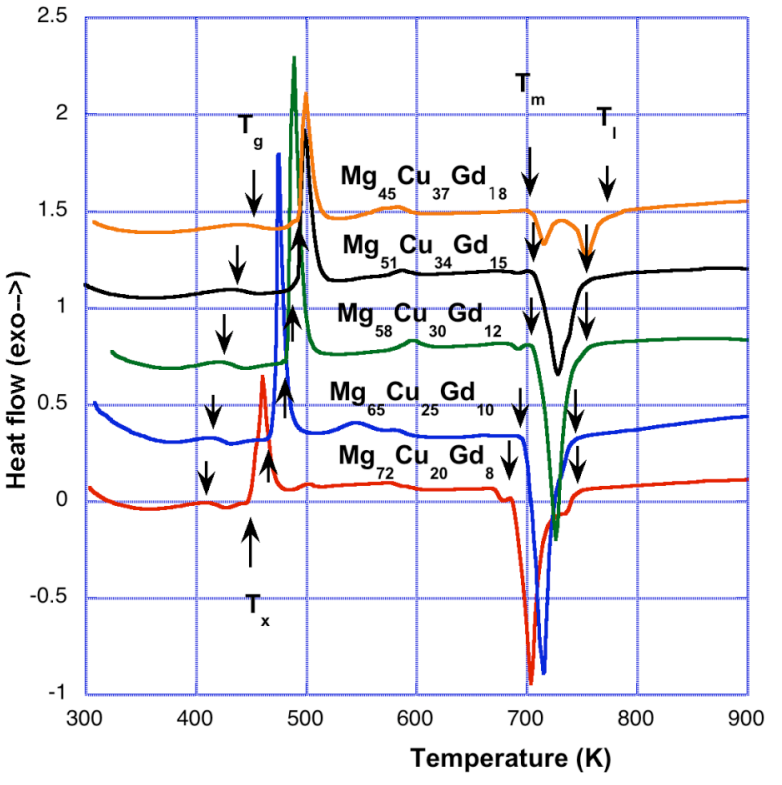

Fig. $4 \mathrm{~b}$ : DSC traces of the $\mathrm{Mg}_{\mathrm{x}} \mathrm{Cu}_{\mathrm{y}} \mathrm{Gd}_{\mathrm{z}} \mathrm{BMG}$ alloys obtained at $10 \mathrm{~K} / \mathrm{min}$.

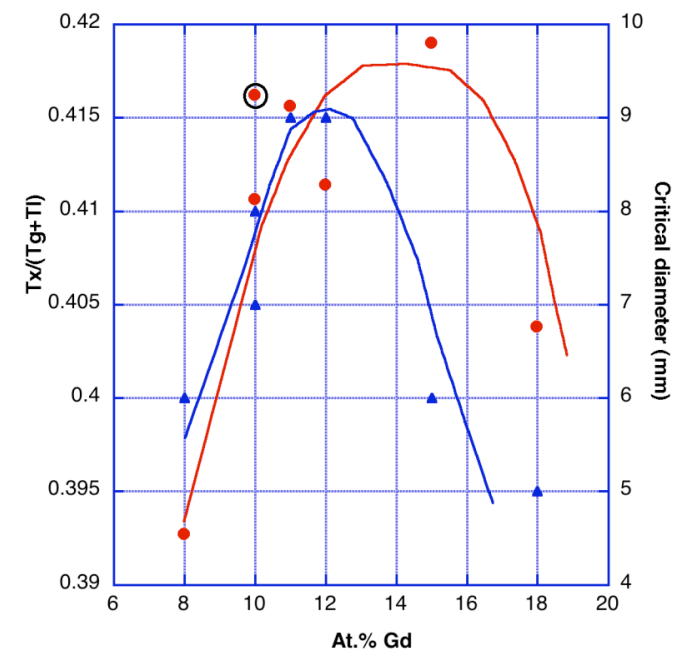

Fig. 5: $\gamma$ parameter and critical diameter as a function of gadolinium content. The lines are a guide for the eyes. Full circles are experimental points for $\gamma$ of this study; triangles are critical diameters; the circle point is from [19]. 